\title{
COMUNIDADE QUILOMBOLA BARRA DA AROEIRA (TO): ABORDAGEM FENOMENOLÓGICA DAS PRÁTICAS ECOLÓGICAS
}

\section{QUILOMBOLA COMMUNITY BARRA DA AROEIRA (TO): PHENOMENOLOGICAL APPROACH OF ECOLOGICAL PRACTICES}

\author{
Rogério Ferreira Teixeira \\ Universidade Federal do Tocantins - Palmas - TO - Brasil \\ Lucas Barbosa e Souza \\ Universidade Federal do Tocantins - Palmas - TO - Brasil
}

\begin{abstract}
Resumo: Esta pesquisa se propôs a investigar a percepção sobre o meio ambiente e as práticas da economia ecológica na Comunidade Quilombola da Barra da Aroeira, localizada no Município de Santa Teresa do Tocantins, Estado do Tocantins, Brasil. Para tanto, foi empregada uma abordagem fenomenológica, tendo como finalidade apreender as possíveis contribuições quanto às práticas sustentáveis em suas diferentes interfaces, a partir da experiência dos próprios moradores locais. Especificamente, foram abordadas questões ligadas à natureza, à produção e ao modo de vida na Comunidade, com a intenção de melhor conhecê-la e de identificar ações efetivas, técnicas e princípios com potencial para a promoção de desenvolvimento local replicáveis em outros contextos, sobretudo no Estado do Tocantins.
\end{abstract}

Palavras-chave: Percepção Ambiental. Desenvolvimento Local. Economia Ecológica.

Abstract: This research aims to investigate the perception about environment and practices of ecological economics in Quilombola Community Barra da Aroeira, located in the city of Santa Teresa do Tocantins, state of Tocantins, Brazil. For that, it has been used phenomenological approach, with the purpose to understand the potential contributions to sustainable practices in its different interfaces, from the experience of the local inhabitants. Specifically, it has been addressed issues related to the nature, production and way of life in the Community, with the intention to know it better and to identify effective actions, techniques and principles with the potential to promote local development replicable in other contexts, especially in the state of Tocantins. Keywords: Environmental perception. Local Development. Ecological Economics. 


\section{Introdução}

Este artigo teve como foco investigar, por meio de uma abordagem fenomenológica, a percepção sobre o meio ambiente e as práticas da economia ecológica na Comunidade Quilombola da Barra da Aroeira, localizada no Município de Santa Teresa do Tocantins, na porção central do Estado do Tocantins. A pesquisa ocorreu entre os meses de setembro de 2010 e agosto de 2011 , tendo como foco a referida Comunidade, por meio de seus moradores.

A Comunidade Quilombola da Barra da Aroeira se localiza 96 quilômetros a leste de Palmas, capital do estado, e a 12 quilômetros da área urbana do Município de Santa Teresa do Tocantins. É constituída por descendentes de escravos, sendo remanescente quilombola devidamente reconhecido pela Fundação Cultural Palmares, possuindo uma associação comunitária, uma escola municipal de ensino fundamental, um posto de saúde, um centro cultural e uma igreja em sua área.

A Comunidade teve sua origem a partir do momento em que seu patriarca, o ex-escravo Félix José Rodrigues, recebeu terras doadas pelo governo brasileiro, por ocasião de sua participação na Guerra do Paraguai (1865 - 1870), como soldado das forças armadas (ZACARIOTI, SIQUEIRA e CASTRO, 2009). Ainda nos dias de hoje, segundo esses mesmos autores, praticamente todos os moradores da Comunidade descendem desse patriarca.

Atualmente, 86 famílias residem na Comunidade, totalizando cerca de 500 pessoas $^{1}$, sendo que, destas famílias, 73 são ligadas à associação comunitária local. A Comunidade mantém-se basicamente com a produção agrícola (que tem uma parte processada, como a mandioca, usada na produção da farinha, e a cana-de-açúcar, que serve de matéria-prima para a rapadura, por exemplo), criação de animais, venda de produtos artesanais e com recursos de algumas pessoas aposentadas ou que trabalham fora de sua área. Um aspecto que limita a produtividade agrícola é o fato da Comunidade ainda não possuir o título definitivo de propriedade da terra, o que impede acesso a financiamentos agrícolas. Embora as terras tenham sido recebidas por

\footnotetext{
1 Dados fornecidos pela Associação Comunitária do local, em visita realizada no dia 25.09.2010.
} 
doação no século XIX e a Comunidade já tenha sido reconhecida como remanescente quilombola, a regularização fundiária ainda não foi concluída, permanecendo em curso.

Algumas características encontradas na Comunidade, como os elementos de sua cultura quilombola, a produção agrícola familiar e os laços afetivos que os moradores mantêm com o lugar, geraram o interesse pela realização desta pesquisa, tomando como principal referencial teórico a economia ecológica e, como método, a fenomenologia.

A economia ecológica surge como campo teórico a partir do final do século XX, mais especificamente na década de 1970, tendo suas análises inicialmente voltadas aos processos de reciclagem de insumos e à minimização de impactos ambientais ${ }^{2}$ no processo produtivo. A economia ecológica pode ser definida, segundo Martinez- Alíer (1998, p. 268), como:

uma economia que usa os recursos renováveis (água, pesca, lenha e madeira, produção agrícola) com um ritmo que não exceda sua taxa de renovação, e que usa os recursos esgotáveis (petróleo, por exemplo) com um ritmo não superior ao de sua substituição por recursos renováveis (energia fotovoltaica, por exemplo). Uma economia ecológica conserva assim a diversidade biológica, tanto silvestre quanto agrícola.

A economia ecológica apresenta inovações significativas na forma de abordar as interações do homem com o meio ambiente, propondo estratégias que minimizem nossa alta produção de entropia e garantam a sustentabilidade da vida (MUELLER, 2007).

Para Ruscheinsky (2004), a sustentabilidade refere-se à capacidade de um modelo ou sistema sustentar-se em sua dinâmica evolutiva, sem permitir que algum setor se aprofunde em crises, de tal

\footnotetext{
2 A Resolução 001 de 23/01/1986 do CONAMA (Código Nacional de Meio Ambiente) em seu artigo $1^{\circ}$ define impacto ambiental como "qualquer alteração das propriedades físicas, químicas e biológicas do meio ambiente, causada por qualquer forma de matéria ou energia resultante das atividades humanas que, direta ou indiretamente, afetem: a saúde, a segurança e o bem-estar da população; as atividades sociais e econômicas; a biota; as condições estéticas e sanitárias do meio ambiente; a qualidade dos recursos ambientais".
} 
forma que venha a atingir a sua totalidade. É nessa mesma perspectiva que iremos nos referir a este termo no âmbito deste artigo.

Eisler (2008), por sua vez, tece uma crítica à economia, afirmando que ela acabou tornando-se, ao longo do século XX, uma ciência pouco interessada em incluir nas suas análises questões como o meio ambiente e as relações humanas, baseando-se, intensivamente em teoremas abstratos e equações matemáticas. Capra (2006) também chama a atenção para a necessidade de o pensamento econômico incorporar, em suas análises, as dimensões ecológica, psicológica e cultural, para a compreensão dos fenômenos econômicos. Após fazer uma minuciosa revisão das principais correntes do pensamento econômico, este autor considera que a ciência econômica tornou-se excessivamente centrada em uma perspectiva newtoniano-cartesiana, baseada no racionalismo científico. Em sua opinião, a ciência econômica precisa se esforçar para adaptar-se às mudanças das estruturas sociais e institucionais de cada época, adquirindo um caráter mais humanista.

É justamente esse viés humanista que justifica a utilização do método fenomenológico para uma abordagem perceptiva junto aos moradores da Comunidade Quilombola Barra da Aroeira. A fenomenologia influenciou a realização dos primeiros estudos perceptivos na área ambiental, porém os pesquisadores foram gradativamente adotando outros referenciais teórico-metodológicos nos trabalhos. Dessa forma, a aplicação direta do método fenomenológico acabou não se tornando uma prática habitual nesses estudos, permanecendo apenas uma relação tênue, pelo caráter humanista e pelo fato de se preocuparem com a subjetividade. Apesar das dificuldades para a aplicação stricto sensu de um método eminentemente filosófico no campo de uma investigação empírica, este artigo teve como premissa resgatar a proximidade genética dos estudos perceptivos do meio ambiente com a fenomenologia.

O método fenomenológico poderá muito bem contribuir com a ciência econômica no fortalecimento das investigações sobre suas bases socioambientais, que valorizem mais os sujeitos e seus aspectos culturais, o que poderá, a partir daí, demonstrar novas possibilidades e ampliar as suas fronteiras de pesquisa, a partir da interdisciplinaridade. Este artigo representa, nesse sentido, uma tentativa de contribuição para o estudo interdisciplinar envolvendo a economia e o meio 
ambiente, a partir da subjetividade dos sujeitos envolvidos nessa relação.

\title{
20 Despertar da Economia Ecológica
}

Desde a Revolução Industrial, o sistema econômico vem se desenvolvendo tendo como fio condutor o grande capital que não reconhece limites para a sua reprodução, impondo danos ao meio ambiente e, muitas vezes, ultrapassando limites éticos. Sen (1999, p. 19) reflete a respeito desse assunto, afirmando que:

\begin{abstract}
em última análise a economia relaciona-se ao estudo da ética e da política, afirmando que o problema da motivação humana, "Como devemos viver?", revela uma questão amplamente ética, ressaltando que essa ligação não equivale a afirmar que as pessoas sempre agirão de maneira que elas próprias defendem moralmente, mas apenas a reconhecer que as deliberações éticas não podem ser totalmente irrelevantes para 0 comportamento humano real.
\end{abstract}

Há também a repercussão social dos impactos ambientais, como a diminuição de recursos naturais em condições de atender às necessidades básicas da população, provocando a proliferação da fome, da miséria e de doenças. A redução das terras férteis com a erosão dos solos diminui a produção agrícola, encarecendo os preços dos alimentos, caso o nível de demanda se mantenha constante. Este é apenas um exemplo do efeito dos impactos ambientais no sistema econômico ${ }^{3}$.

Sobre esse contexto socioambiental, Mueller (2007, p. 76) comenta que:

até meados do século XX os impactos ambientais da escala da economia não pareciam constituir, pelo menos em termos globais, ameaça ao bem-estar da humanidade. Não se

\footnotetext{
3 Outros exemplos dos efeitos dos impactos ambientais na economia são os contínuos aumentos dos gastos públicos para tratar pessoas vítimas de complicações respiratórias devido à poluição atmosférica e para tratamento da água poluída por esgoto doméstico e industrial, ambos os casos geralmente em grandes concentrações urbanas.
} 
considerava que a disponibilidade de recursos naturais de nosso globo pudesse vir a limitar a expansão da economia mundial. Além disso, as emanações e o despejo de resíduos e dejetos no meio ambiente provocavam apenas desconfortos localizados, que o desenvolvimento tecnológico acabava por reverter.

Para a corrente neoclássica, a economia podia crescer sem a preocupação com o esgotamento dos recursos naturais, simplesmente apoiando-se na expansão da força de trabalho e na acumulação do capital físico construído (MUELLER, 2007). Pela segunda lei da entropia (aumento da desordem no sistema), é impossível um sistema fechado prosseguir seu crescimento indefinidamente, captando energia de baixa entropia e liberando resíduos de alta entropia no ecossistema, pois há um limite para a absorção e a reciclagem destes resíduos. Tal fato é ignorado pela teoria econômica convencional (neoclássica). Assim sendo, os impactos ambientais podem acabar restringindo 0 crescimento econômico (CECHIN e VEIGA, 2010).

A partir da preocupação de alguns economistas com o meio ambiente e a sustentabilidade das atividades humanas em longo prazo, como Nicolas Georgescu-Roegen, Keneth Boulding e Herman Daly, a dimensão ambiental foi sendo incorporada na construção dos modelos e teorias da ciência econômica, dando origem, então, à economia ecológica.

Georgescu-Roegen (1971) aponta que os principais postulados da economia ecológica são: a utilização de processos de reciclagem, a minimização do uso de energia e de materiais, a consideração do custo ambiental decorrente de todo o processo de extração, produção e consumo e a minimização da produção de dejetos e da poluição. Segundo sua análise, a entropia coloca limites para a expansão contínua das atividades, dada a finitude dos recursos naturais do planeta.

O fundamento central da economia ecológica é a escala em que o sistema econômico opera em relação ao ecossistema. Além de uma escala ótima, o seu crescimento pode acarretar mais prejuízos do que benefícios à humanidade (CECHIN e VEIGA, 2009).

Martinez-Alíer (1998) apresenta duas figuras em que diferencia a abordagem da economia ecológica da economia neoclássica. Na Figura 1 , presente na grande maioria dos manuais, a economia é analisada 
como um sistema lubrificado pelo dinheiro, em que as empresas vendem bens e serviços e remuneram os fatores de produção (terra, trabalho e capital).

Figura 1. Funcionamento da economia na perspectiva da Economia Convencional

Mercados

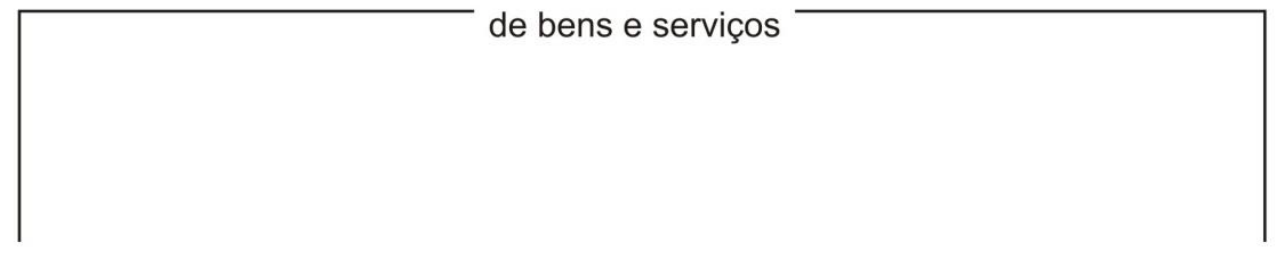

$\begin{array}{ccc}\text { Empresas } & \begin{array}{c}\text { Economia } \\ \text { Neoclássica }\end{array} & \text { Famílias }\end{array}$

Mercados de fatores de produção

Fonte: Martinez-Alier (1998, p.54)

Na Figura 2, baseada na economia ecológica, a Terra é analisada como um sistema aberto à entrada de energia solar. A economia demanda entrada de recursos e materiais, produzindo resíduos e calor dissipado (de acordo com a segunda lei da termodinâmica). Uma parte dos resíduos materiais pode ser reciclada como matéria-prima. A manutenção do sistema econômico exige um fornecimento adequado de energia e de materiais, além da manutenção do equilíbrio dos ecossistemas para continuar operando. 
Figura 2. Funcionamento da economia na perspectiva da Economia Ecológica

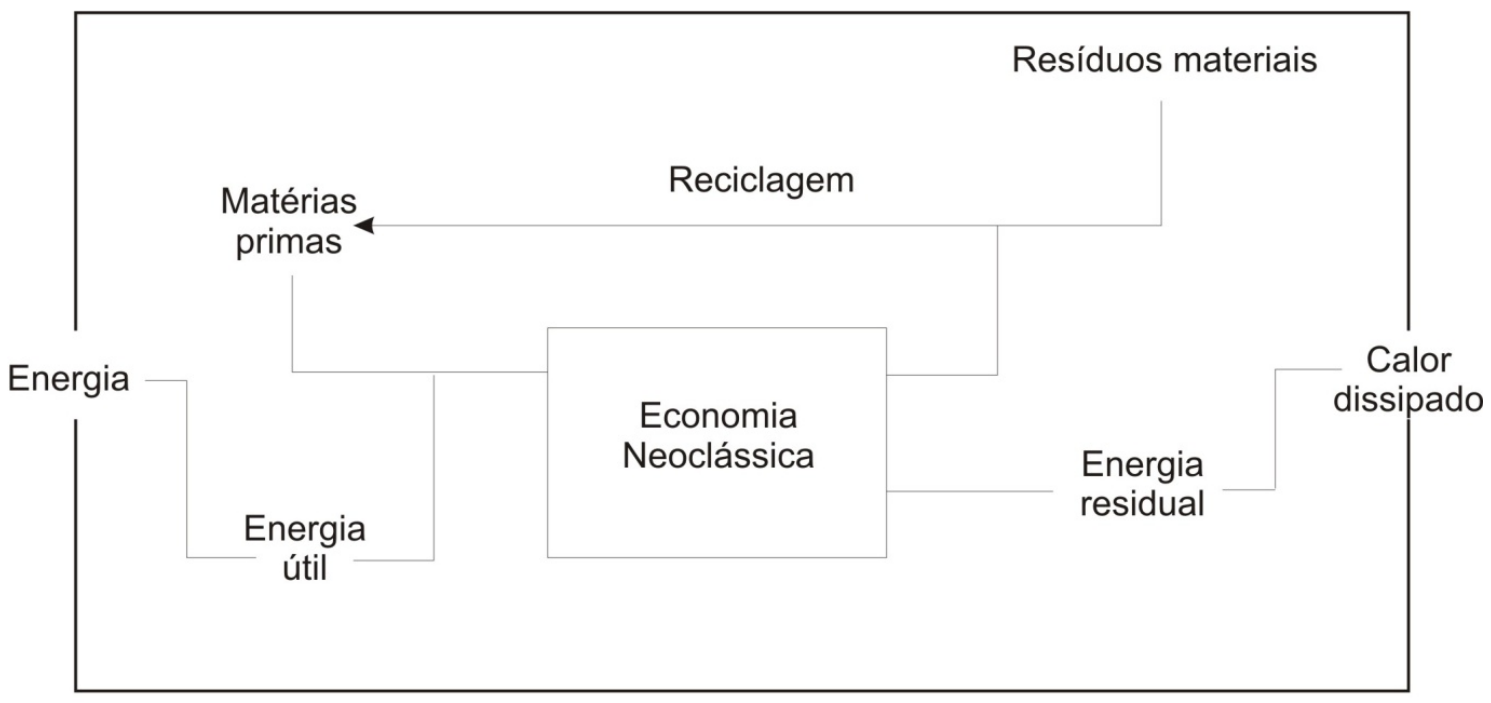

Fonte: Martinez-Alier (1998, p.54)

Daly (1984) propôs a "economia do estado-estável", que consistiria em suprimir a obstinação pelo crescimento econômico ilimitado. Em sua opinião, um nível de crescimento com estabilidade é necessário para gerenciar as relações econômicas minimizando a pressão antrópica sobre o meio ambiente. A ênfase na política econômica, segundo o autor, estaria, deste momento em diante, em gerenciar o estoque de recursos existentes e não mais o fluxo econômico. Apesar de contribuir para uma mudança de paradigma, tais sugestões têm muitas limitações na sua exequibilidade, sendo a principal delas quanto à determinação do nível desejável para estabilizar o crescimento econômico ${ }^{4}$. Como definir, então, um nível de consenso com tantas disparidades entre países desenvolvidos e subdesenvolvidos, por exemplo?

Por conseguinte, a grande questão que permanece sem resposta ainda nos dias de hoje é qual seria a "escala ótima" em que o volume de bens e serviços produzidos pelo sistema econômico se tornaria compatível com a capacidade do planeta em absorver os resíduos de alta entropia gerados. O panorama ambiental global dá mostras visíveis

\footnotetext{
4 Convém ressaltar que uma das premissas básicas do comportamento do consumidor, segundo a teoria microeconômica, é a de que uma quantidade maior de bens normais é sempre preferível, mesmo tratando-se de uma quantidade não significativa. Esse axioma também é conhecido como o da não-saciedade (PINDYCK e RUBINFELD, 2005).
} 
de saturação há várias décadas e uma das saídas habitualmente apontadas é a utilização de tecnologia e inovação. Todavia, não é prudente acreditar, como alguns teóricos da economia convencional (neoclássica), que se pode substituir produtos e serviços ambientais por recursos tecnológicos no intuito de manter a curva exponencial de crescimento econômico por tempo indeterminado (MUELLER, 2007).

M'Gonigle (1999) distingue duas correntes na economia ecológica: uma associada a uma análise baseada em formalismos técnicos (de vertente neoclássica), em que o meio ambiente é analisado como mais um recurso para finalidades econômicas, e outra de abordagem mais ampla, que engloba um olhar profundo sobre os contextos institucionais, em que são analisadas as interações da sociedade, da política, da cultura e do meio ambiente com a ciência econômica. Todavia, essas abordagens não são consideradas mutuamente excludentes, mas complementares.

Söderbaum (1999), por seu turno, reforça nossa concepção da economia ecológica afirmando que seus recursos-chave são: trabalho para uma sociedade sustentável com um senso ecológico, prontidão para encaminhar as questões fundamentais de quadros conceituais e de valores, interação com acadêmicos de outras disciplinas e observação dos imperativos essenciais da democracia. Desse modo, o autor afirma que a economia ecológica pode interagir com diferentes áreas, como a ciência política e a gestão de negócios, por exemplo. Acrescentaríamos aqui a possibilidade da utilização da fenomenologia como método de estudo de situações concretas em economia ecológica, com privilégio para os aspectos subjetivos oriundos dos próprios sujeitos envolvidos com essa prática.

Para Melo (2006), a análise dos fluxos físicos de energia e de materiais é um pressuposto importante da economia ecológica, além da consideração dos preços de mercado com o devido rigor em suas análises, uma vez que estes podem esconder relações ecologicamente desiguais. Ressalta, também, que a economia ecológica advoga uma participação política ativa dos ambientalistas, a fim de pressionar a sociedade para que o meio ambiente receba a atenção adequada dos gestores públicos na elaboração de projetos e na formulação de políticas específicas para as suas demandas. 
Martine (2007) propõe que uma estratégia prática para minimizar impactos ambientais seria estudar a distribuição populacional em um território, focando no seu uso sustentável de acordo com os recursos disponíveis, a população, o potencial econômico e o contexto atual de desenvolvimento, para atingir índices toleráveis de crescimento econômico e social, embora isso também se constitua em uma tarefa complexa. Logo, tal visão nos remete à perspectiva do desenvolvimento segundo uma dimensão local.

Segundo Tenório (2007), o desenvolvimento local é uma abordagem que procura reforçar a potencialidade do território mediante ações endógenas, articuladas pelos seus diferentes atores (sociedade civil, poder público e mercado). De acordo com o autor, o desenvolvimento local pressupõe a reciprocidade, a cooperação e a solidariedade em benefício do bem-estar socioeconômico, político, cultural e ambiental na escala local, podendo assumir três vertentes: econômica, guiada por parâmetros de mercado; social, orientada pela cooperação e solidariedade; ou híbrido, onde há orientação econômica e cooperativa, estimulando o fomento de capital social 5 .

5 Para Baquero (2007), o capital social nasce de interações cotidianas, não de legislações. Promove a participação coletiva e o engajamento das pessoas em projetos de desenvolvimento comunitário e sustentável. Gera empoderamento dos atores sociais, o que por sua vez possibilita bem-estar e qualidade de vida. 
A permacultura tem sido usada para o manejo ambiental em comunidades sustentáveis ${ }^{6}$, constituindo-se em uma ferramenta valiosa para a economia ecológica nestes espaços, possibilitando ganhos produtivos no cultivo da terra, reciclagem e reutilização de materiais, e o aperfeiçoamento de técnicas ancestrais para uma vida sustentável como, por exemplo, as construções com materiais da natureza (barro e palha de grama).

Sobre a permacultura, Legan (2004, p.13) nos esclarece que:

permacultura significa cultura permanente. É um sistema de
design para a criação de ambientes produtivos, sustentáveis e
ecológicos para que possamos habitar na Terra sem destruir a
vida. Este sistema de planejamento holístico trabalha com a
natureza pela imitação dos processos naturais, utilizando a
sabedoria dos sistemas tradicionais de produção e o
conhecimento científico moderno para estabelecer
comunidades sustentáveis.

O conceito foi desenvolvido na década de 1970 por dois australianos: David Holmgren e Bill Mollison. Consiste no desenho e manutenção de pequenos ecossistemas produtivos, junto com a integração harmônica do entorno, das pessoas e suas vidas, proporcionando respostas a suas necessidades de uma maneira sustentável. De acordo com Legan (2004), o princípio básico da permacultura é o de trabalhar "com" ou "a favor de", e não "contra" a natureza. Os sistemas permaculturais são construídos para durar tanto quanto seja possível, com um mínimo de manutenção. Os sistemas são tipicamente energizados pelo sol, o vento e a água, produzindo o suficiente tanto para sua própria necessidade como para a dos humanos que o criam e controlam. Dessa maneira, o sistema é considerado sustentável.

Nesse sentido, segundo Capra (2002), a lógica predominante do sistema capitalista é a competição e não a solidariedade, o que contraria o padrão de sustentabilidade da vida no planeta. Desse modo, a

6 Conforme relata Santos Jr. (2006), há comunidades sustentáveis espalhadas pelo mundo todo, como em Findhorn (Escócia), Cristal Waters (Austrália) e Lebensgarten (Alemanha), reconhecidas internacionalmente como referências em práticas ecológicas utilizando as técnicas da permacultura. 
economia ecológica pode ofertar à ciência econômica um resgate de valores humanistas primordiais, para que se tenha alternativas sustentáveis voltadas a uma vida digna, tanto no presente quanto no futuro.

\section{A fenomenologia e o método fenomenológico}

A fenomenologia, corrente filosófica desenvolvida por Edmund Husserl na Alemanha, entre o final do século XIX e o início do século XX, constitui a base para a abordagem perceptiva empregada neste artigo. Moreira (2004) explica que a palavra fenomenologia deriva do grego, em que phainomenon significa aquilo que se mostra a partir de si mesmo, enquanto logos significa ciência ou estudo. De acordo com as palavras do próprio Husserl (2008, p.85), "a fenomenologia procede elucidando visualmente, determinando e distinguindo o sentido, sendo, pois, ciência num sentido totalmente diferente, com tarefas inteiramente diversas e com um método completamente distinto". Portanto, a fenomenologia é a ciência ou estudo dos fenômenos, do que se manifesta ou se revela por si mesmo (BELLO, 2004).

Giorgi (2008) comenta que Husserl exerceu influência sobre vários pensadores, dentre eles Heidegger, Scheler, Sartre e Merleau-Ponty. Todavia, eles se distanciaram tanto de Husserl, quanto uns dos outros, adotando diferentes modos de interpretar a fenomenologia. De um modo semelhante, os primeiros estudos no campo da percepção ambiental tiveram como inspiração a fenomenologia, porém foram se distanciando dessa corrente com o tempo, na medida em que foram gradativamente incorporados outros referenciais oriundos da filosofia e da psicologia. Essa trajetória contribuiu para que os estudos perceptivos do meio ambiente passassem a apresentar somente um espírito fenomenológico, ao invés de uma aplicação mais rigorosa do método fenomenológico, conforme pensado originalmente por Husserl (HOLZER, 1998).

Chauí (2005) sustenta que Husserl desenvolveu um método a fim de compreender o significado dos fenômenos, ou seja, a redução fenomenológica. Com essa operação, a existência efetiva (concreta, factual) do mundo exterior é colocada entre parênteses, para que a investigação se ocupe apenas com as operações realizadas pela 
consciência dos sujeitos, sem que se pergunte se as coisas visadas por ela existem realmente ou não. De acordo com Husserl (2006, p.143), "[...] se, portanto, tomamos os vividos puramente em sua essência própria, então se abre para nós, segundo tudo o que foi apresentado, um campo de conhecimentos eidéticos". O autor enfatiza, ainda, que

o que quer que possa ser eideticamente apreendido nos vividos reduzidos em intuição pura - quer como componente real, quer como correlato intencional - será próprio a ela, e tal é para ela uma grande fonte de conhecimentos absolutos (HUSSERL, 2006, p.161).

A redução fenomenológica, conforme criada por Husserl, é composta por dois momentos. No primeiro, a redução eidética procura destacar as essências ou significados dos fenômenos para os sujeitos investigados. No segundo momento, a redução transcendental visa à essência da própria consciência desses sujeitos, enquanto produtora de essências ideais. Nesse sentido, coloca-se de lado a existência factual dos fenômenos, evidenciando a sua manifestação para os sujeitos. 0 autor explicita que "a toda a vivência psíquica corresponde, pois, por via da redução fenomenológica, um fenômeno puro, que exibe a sua essência imanente (singularmente tomada) como dado absoluto" (HUSSERL, 2008, p.69).

Bello (2004, p. 90), por sua vez, assim explica a análise fenomenológica:

a análise fenomenológica do perceber supera o plano da percepção e atua no nível de uma outra vivência que é a reflexão. Trata-se da vivência da reflexão, diversa da percepção e importantíssima para o ser humano. Podemos dizer também que refletir significa ter consciência: nesse caso, a consciência corresponde a um primeiro saber algo, não a uma reflexão sobre algo.

O método fenomenológico permite conhecer os elementos da subjetividade, por meio das vivências do indivíduo, o que compreende a sua percepção, pensamento, lembrança e imaginação, buscando descortinar os significados que ele lhes outorga. Ferraz (2004) considera que a fenomenologia não tem a pretensão de restringir $o$ horizonte da racionalidade, mas expandi-lo até a sua raiz sensível. Para 
o autor, o mundo da vida husserliano (/ebenswe/t) é o local onde os fenômenos reúnem-se em sistemas de relações. Isso significa que as interconexões entre eles estão sempre presentes, o que Ihes confere diferentes significados, conforme o contexto em que são apreendidos. Segundo Husserl, as "[...] percepções de coisas são vividos originários em relação a todas as recordações, presentificações de imaginação etc." (HUSSERL, 2006, p.173).

Coltro (2000) é enfático ao afirmar que o mundo da vida é onde se encontram as crenças, os princípios, valores e atitudes do sujeito. $\mathrm{Na}$ pesquisa realizada, o mundo da vida dos sujeitos abordados é a Comunidade Quilombola Barra da Aroeira, local onde exercem suas atividades produtivas, desempenham suas práticas associativas, relacionam-se com o ambiente e vivem com suas famílias.

Boava e Macedo (2008, p. 9) afirmam que:

O método fenomenológico busca captar as essências do que o homem vivenciou. Mas esse homem vive em grupo, em uma sociedade. Ele é mutável, efêmero, perturbado por motivações obscuras. Ele é influenciado pela mídia, por sua família, sensível aos valores.

$\mathrm{Na}$ fenomenologia, o conceito de intencionalidade, que Husserl buscou na psicologia descritiva de Franz Brentano, desempenha um papel central. A intencionalidade é construída a partir da relação seletiva da psique com os objetos. O caráter intencional da consciência, em última instância, acaba definindo o status dos atos psíquicos dos sujeitos (BELLO, 2004). "A intencionalidade é aquilo que caracteriza a consciência no sentido forte, o que justifica ao mesmo tempo designar todo o fluxo de vivência como fluxo de consciência [...]" (HUSSERL, 2006, p.190).

Ainda segundo Husserl (2006, p.171), "ora, por lei de essência, todo vivido pode passar por modificações reflexivas, e em diferentes direções [...]" Essa afirmação do filósofo abre espaço para o transporte do método fenomenológico para o campo científico, pois não fecha as portas para a descoberta de essências científicas, considerando também a intencionalidade própria de cada ciência. É isso que se empreende ao selecionar as unidades de significação, segundo Giorgi (2008), pois se realizam recortes de interesse nas descrições amplas dos sujeitos, de 
acordo com os objetivos da pesquisa e os interesses disciplinares específicos.

Husserl (2005) enfatiza que a percepção é um ato que determina a significação, sem que, no entanto, a contenha. Observando, pois, suas próprias palavras, o autor nos explica que "uma intenção dirigida a um objeto, uma vez concebida a partir de uma intenção conveniente, pode ser repetida e recriada em consonância, sem a mediação de uma percepção ou de uma afiguração que de alguma maneira the seja adequada" (HUSSERL, 2005, p.40).

Moreira (2002) realiza uma análise minuciosa sobre o transporte da fenomenologia, enquanto campo filosófico, para sua aplicabilidade como instrumento de pesquisa, abordando vários autores, os quais a validam como metodologia de pesquisa qualitativa empírica eficiente quando se trata de analisar questões relacionadas a aspectos subjetivos ligados à experiência vivida. 
Nessa pesquisa, especificamente, iremos adotar os procedimentos sugeridos por Giorgi (2008) devido a sua operacionalidade perante as características do mundo vivido dos sujeitos. O autor ressalta que, para uma pesquisa ser considerada fenomenológica, é necessário atentar para a descrição minuciosa das vivências dos sujeitos (e não às suas opiniões sobre algo), realizar ao menos um tipo de redução (eidética ou transcendental) e construir estruturas próprias à disciplina, por meio de variações livres ou imaginárias, para dar significação científica ao que foi descrito. Carvalho e Vergara (2002) destacam que na fenomenologia não há formulação de hipóteses, mas a indução criativa, partindo dos fatos para a teoria7. Assim, os sentidos são revelados pelos próprios sujeitos, sem que uma hipótese prévia seja estabelecida e testada pelo pesquisador. Com base nessas premissas, buscou-se a construção de uma proposta operacional para a utilização do método fenomenológico na pesquisa sobre a Comunidade Quilombola Barra da Aroeira.

\section{0 passo-a-passo da investigação}

No campo da percepção ambiental, Whyte (1977) considerou três atitudes básicas que contribuem para os estudos perceptivos do meio ambiente, quais sejam: observando, ouvindo e perguntando. Neste artigo, foram selecionados os resultados obtidos a partir da utilização das abordagens ouvindo (por meio da qual se operacionalizou o método fenomenológico) e observando, com enfoque nos aspectos ambientais e nas práticas da economia ecológica na Comunidade Quilombola Barra da Aroeira.

Para atender à estratégia ouvindo, foi formulada uma única questão a ser respondida pelos sujeitos, respeitando os procedimentos do método fenomenológico. Essa questão buscou a descrição das suas vivências na Comunidade, procurando-se evidenciar seus sentidos quanto às relações com a terra, a conduta de manejo e de uso dos recursos naturais e a atribuição de valor ao ambiente vivido.

A coleta das descrições teve início com as duas principais lideranças da Comunidade (atual e ex-presidente da Associação

\footnotetext{
7 Segundo Husserl, "as teorizações dedutivas estão excluídas da fenomenologia" (HUSSERL, 2006, p.162).
} 
Comunitária dos Quilombos da Barra da Aroeira). Posteriormente, buscou-se ampliar o grupo de sujeitos, pela escolha aleatória de outros indivíduos na Comunidade, com a preocupação de respeitar o equilíbrio entre o número de homens e de mulheres. O total de descrições coletadas foi de 17, sendo que nove foram de mulheres e oito de homens. Não foram abordados outros sujeitos na estratégia ouvindo porque as respostas começaram a se tornar semelhantes, indicando a saturação empírica, fenômeno observado em pesquisas qualitativas, onde não há o acréscimo substancial de novas informações e conhecimentos (PIRES, 2008). 
As respostas de cada sujeito foram transcritas na íntegra, imediatamente após a coleta dos dados, para que a riqueza de detalhes observada (expressões, gestos e reações) fosse preservada e fielmente documentada (VENÂNCIO e PESSÔA, 2009). A redução fenomenológica das descrições teve a preocupação de adequar a linguagem transcrita inicialmente para uma linguagem própria da economia ecológica, área do saber que serviu como base teórica da pesquisa, para posterior identificação das essências para os sujeitos, seguindo os procedimentos descritos por Giorgi (2008) para a aplicação do método fenomenológico em pesquisas empíricas.

A técnica de observação, também empregada na investigação, tomou como base as recomendações de Whyte (1977) e serviu para balizar as discussões, ora na qualidade de exemplos, ora na qualidade de constatação ou de confrontação das essências identificadas entre os sujeitos. Para tanto, a utilização da observação indireta possibilitou a verificação in loco de indicadores ambientais da conduta e das ações dos sujeitos em sua prática cotidiana, por meio da conservação do meio ambiente ou da presença de impactos ambientais, por exemplo.

A discussão dos resultados tomou como base a síntese das essências identificadas no conjunto das descrições dos sujeitos. A título de exemplo, foram selecionadas algumas descrições, com suas respectivas reduções fenomenológicas, no sentido de evidenciar as essências identificadas, conforme procedimentos orientados por Giorgi (2008).

\section{Descrições sobre o meio ambiente e as práticas ecológicas na Comunidade Quilombola Barra da Aroeira}

A Comunidade Quilombola da Barra da Aroeira está localizada no Município de Santa Teresa do Tocantins, na porção central do Estado do Tocantins e a cerca de $100 \mathrm{~km}$ a leste da capital estadual, Palmas. Sua distância em relação à área urbana (sede) do município é de aproximadamente $12 \mathrm{~km}$, igualmente a leste, conforme demonstra o mapa a seguir na Figura 3. 
Figura 3. Localização da Comunidade Barra da Aroeira.

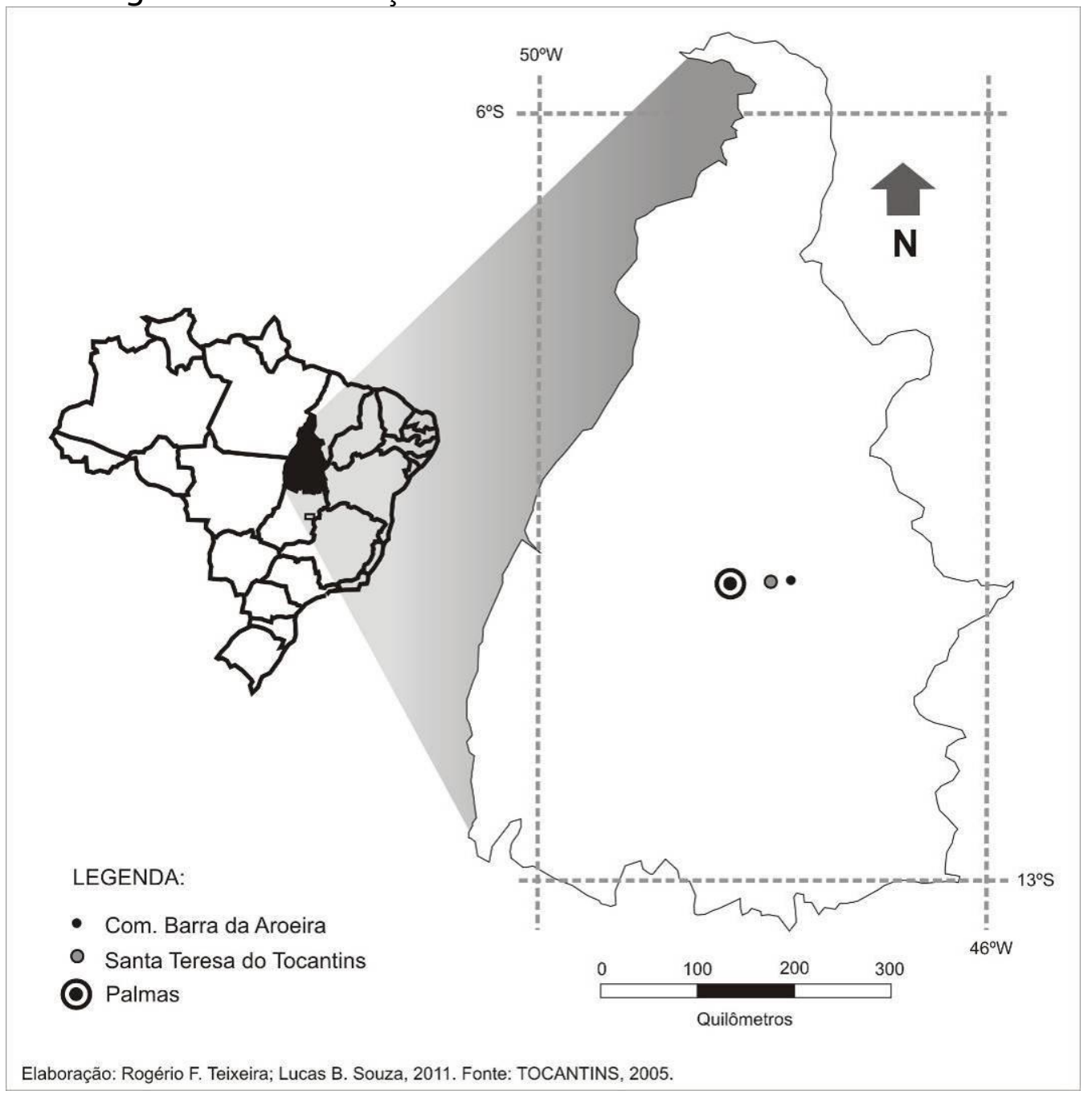

Por meio do enunciado apresentado aos sujeitos, "descreva o que a natureza oferece para vocês viverem aqui e como vocês lidam com ela", buscou-se obter descrições sobre diferentes aspectos ambientais no âmbito da Comunidade, bem como sobre as relações estabelecidas com esse ambiente vivido. As descrições obtidas, após passarem pelos procedimentos de redução fenomenológica e identificação de essências, deram origem ao Quadro 1, que contém a representação da síntese dos resultados alcançados. 
Quadro 1. Essências identificadas nas descrições dos sujeitos da Comunidade Quilombola da Barra da Aroeira

\begin{tabular}{|c|c|c|}
\hline Essências Identificadas & Descrições & $\begin{array}{c}\text { Frequência n } \\
=17\end{array}$ \\
\hline $\begin{array}{c}\text { Natureza como fonte de } \\
\text { subsistência }\end{array}$ & $\begin{array}{c}\text { D1, D2, D3, D4, D5, D6, D7, } \\
\text { D8, D9, D10, D1 1, D12, D13, } \\
\text { D14, D15, D16, D17 }\end{array}$ & 17 \\
\hline $\begin{array}{c}\text { Preocupação com o manejo } \\
\text { ambiental }\end{array}$ & D1, D7, D8, D10, D1 1, D13 & 6 \\
\hline $\begin{array}{c}\text { Preocupação com a } \\
\text { sustentabilidade }\end{array}$ & D1, D2, D3, D4 & 4 \\
\hline $\begin{array}{c}\text { Preocupação com os impactos } \\
\text { ambientais }\end{array}$ & D1, D3, D17 \\
\hline $\begin{array}{c}\text { Resiliência frente às restrições } \\
\text { ambientais }\end{array}$ & D8, D9, D14 & 3 \\
\hline $\begin{array}{c}\text { Facilidade atual para o cultivo da } \\
\text { terra }\end{array}$ & D6 & 1 \\
\hline $\begin{array}{c}\text { Trabalho para o cultivo da terra } \\
\text { Resignação frente aos impactos } \\
\text { ambientais observados }\end{array}$ & D11 & 1 \\
\hline
\end{tabular}

Fonte: Pesquisa de campo dos autores.

A natureza como fonte de subsistência emerge como essencial na percepção de todos os sujeitos abordados. A terra é descrita como fundamental para o cultivo dos alimentos, pois a maior parte dos membros da Comunidade não dispõe de salários, a não ser aqueles que trabalham fora da Comunidade ou que recebem aposentadoria. A descrição D2 (Sujeito de 24 anos, sexo feminino), a seguir, evidencia como a natureza é destacada para os moradores da Comunidade no que tange à sua subsistência:

sem ela a gente não consegue sobreviver. Geralmente a natureza oferece tudo de bom pra gente. Sem ela a gente não consegue sobreviver. Nós precisamos das matas, das terras. Geralmente nós temos um bocado de terras. Nós precisamos da terra, nós não temos salário nenhum para sobreviver. Sem a terra nós não temos como plantar os alimentos.

Empregando o expediente da redução fenomenológica, pode-se perceber que a natureza aparece como elemento fundamental para a sobrevivência na Comunidade, a partir da terra, usada para o plantio 
dos alimentos, pois praticamente não possuem outros recursos para se sustentar. Porém, pode-se deduzir que, embora o plantio diminua a dependência dos moradores do mercado convencional de alimentos, aumenta sua dependência dos recursos naturais no âmbito da própria Comunidade e a fragilidade da sua subsistência frente aos impactos ambientais, o que exige procedimentos de manejo adequados no sentido de proporcionar a manutenção da qualidade ambiental. Nesse sentido, a observação das contribuições de Martine (2007) para o planejamento e uso sustentável dos recursos naturais, considerando a abordagem do seu território quilombola, torna-se importante para a Comunidade se precaver contra efeitos nocivos em seu ambiente.

As plantas e frutas com propriedades medicinais também são referidas em uma descrição (D1 1). A utilização do óleo de pequi para a produção de sabão e para remédio são alternativas sustentáveis que os membros da Comunidade desenvolveram para sua subsistência. É feito o uso do óleo de macaúba no desjejum, em substituição à margarina e à manteiga, o que também representa alternativa sustentável, pois assim eles não necessitam comprar produtos no mercado. Dessa forma, economizam recursos financeiros. Muitos outros alimentos e recursos vegetais e animais são produzidos na própria comunidade, como mandioca, milho, feijão, abóbora, melancia, abacaxi, quiabo, maxixe, tomate, pimenta, arroz, galinhas, coelhos, porcos, preás, entre outros. Sendo uma produção de baixa escala (para consumo próprio e, eventualmente, venda em feiras locais) os riscos de uma super exploração dos recursos são reduzidos, embora a determinação de um nível ótimo de alocação dos recursos naturais da Comunidade, na perspectiva de Cechin e Veiga (2010), não seja viável neste momento, do ponto de vista objetivo. A figura 4, a seguir, demonstra a produção agrícola familiar na Comunidade.

Figura 5. Canteiros de hortaliças 


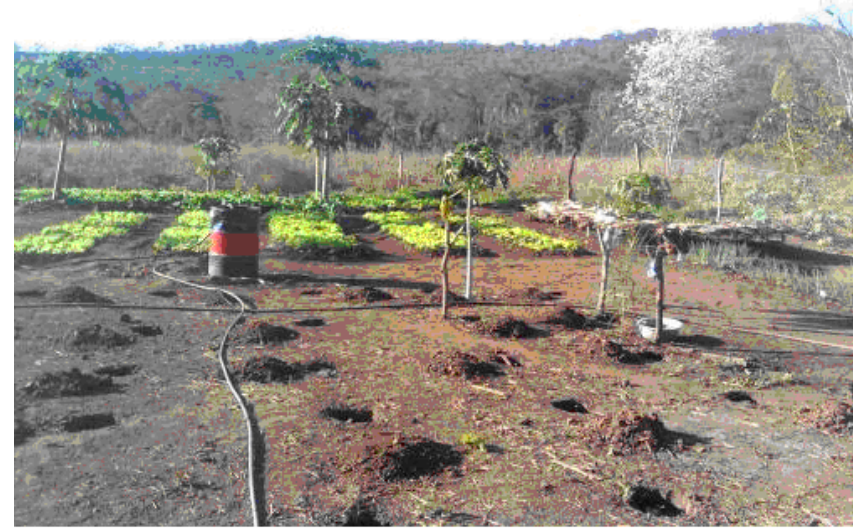

Autor: Rogério Ferreira Teixeira, 2011.

Os sujeitos evidenciam em suas práticas cotidianas a aplicabilidade de muitas técnicas da permacultura, conforme descrita por Legan (2004), tanto na alimentação, como na habitação (observadas no uso do barro e da palha de buriti para as construções), na saúde e no manejo ambiental (observadas na utilização de canteiros suspensos próximos às casas para controle das pragas, por exemplo). As figuras 6 e 7, a seguir, evidenciam este aspecto. 
Figura 6. Horta suspensa

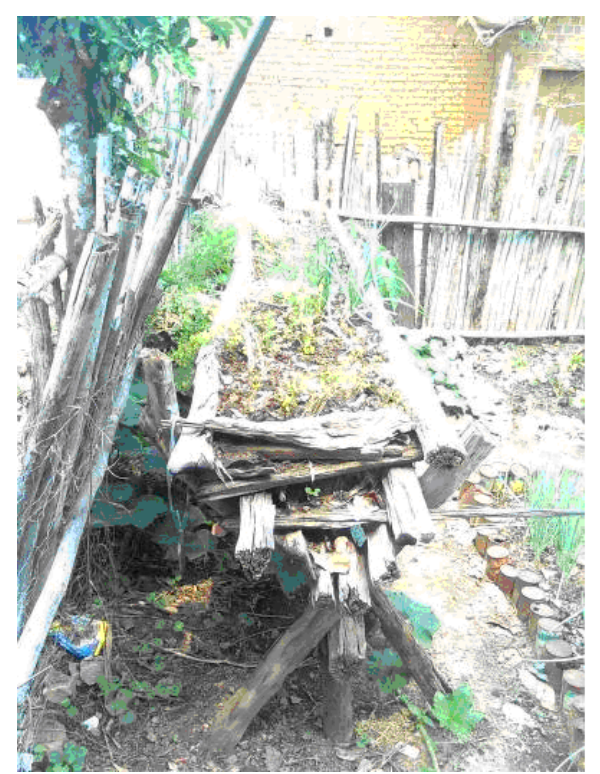

Autor: Rogério Ferreira Teixeira, 2010.

Figura 7. palha de

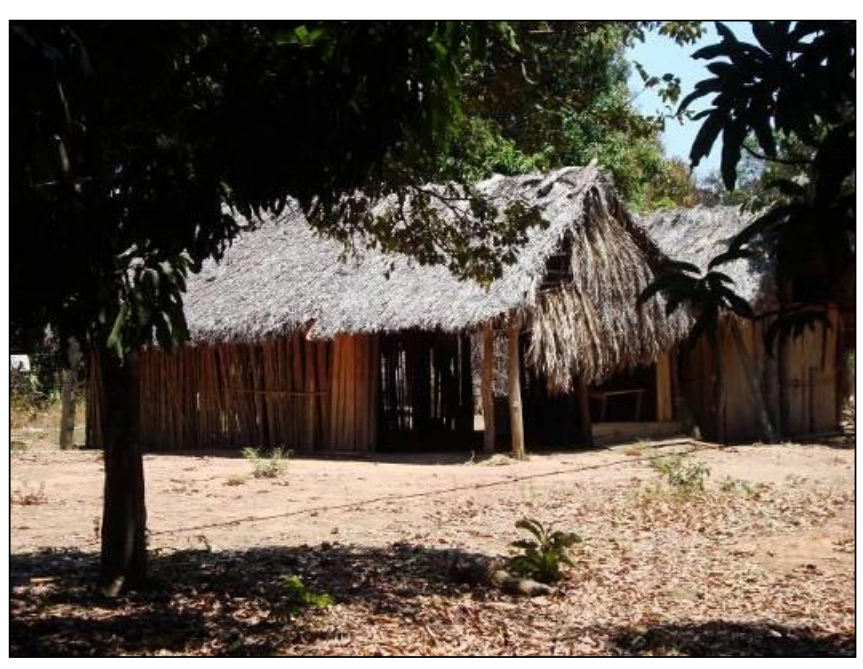

Telhado de buriti

Autor: Rogério Ferreira Teixeira, 2010.

Há uma preocupação dos moradores da Comunidade com o uso sustentável dos seus recursos naturais e o manejo ambiental, contemplando a reciclagem de matéria e energia e os resíduos dos 
processos produtivos, princípios da economia ecológica salientados por Martinez-Alíer (1998) e Georgescu-Roegen (1971), considerando-se os impactos ambientais que acontecem na sua área. Esses fenômenos são destacados nas descrições de dez sujeitos (D1, D2, D3, D4, D7, D8, D10, D11, D13 e D17). As queimadas e o corte de árvores, principalmente as que compõem as matas ciliares, foram referidos nas descrições como os impactos ambientais mais frequentes que ocorrem na Comunidade.

Todavia, apesar dessa preocupação, verifica-se que muitos dos impactos ambientais são desencadeados pelos próprios membros da Comunidade, como parte de suas ações habituais de manejo para a produção de alimentos. A queimada na área da Comunidade (habitualmente observada na época da seca) é um exemplo de manejo costumeiro da pastagem nativa e de prática usual para "limpeza" dos terrenos agricultáveis, o que, contudo, coloca em risco áreas vizinhas e as próprias habitações dos moradores.

Outro impacto ambiental observado na área da Comunidade são depósitos de lixo espalhados em algumas áreas. Os impactos ambientais poderão contribuir para uma situação de fragilidade futura na Comunidade, se for considerada a dependência dos moradores em relação aos recursos naturais, a começar pela própria alimentação. Nesse sentido, a dependência em relação às cestas básicas recebidas regularmente poderá substituir a dependência da terra, a partir do momento em que os impactos ambientais comprometam a qualidade e a disponibilidade de determinados recursos, como a água, os produtos do extrativismo e a fertilidade do solo (pela retirada da cobertura vegetal e pelas queimadas, por exemplo). Desse modo, seria desejável a consideração dos fluxos de energia e matéria na Comunidade por parte de seus moradores, a fim de minimizar a entropia no ecossistema local, como preconiza a economia ecológica (GEORGESCU-ROEGEN, 1971; MELO, 2006; CECHIN E VEIGA, 2010).

A descrição D3 (Sujeito de 21 anos, sexo feminino), a seguir, exemplifica na sua essência as percepções dos moradores no que se refere aos impactos ambientais, ao manejo ambiental e à sustentabilidade na Comunidade:

a terra daqui é muito boa, ela oferece assim para o plantio. $\mathrm{O}$ plantio que a gente planta é muito bom, mas não deveria ter 
tanta queimada. O povo corta muita árvore na beira dos córregos, o córrego tá secando, mas é muito bom o plantio aqui, só não deveria ter esse desgaste que tá acabando com a natureza.

Utilizando o método da redução fenomenológica, pode-se perceber que a descrição revela uma preocupação com a questão da subsistência, dos impactos ambientais e da conservação do córrego que corta a área da Comunidade. A terra, mais uma vez, é referida como fator importante e de qualidade para a sua manutenção.

Três sujeitos (D8, D9 e D14) revelaram em suas descrições a capacidade de resiliência ${ }^{8}$, ou seja, a capacidade que os membros da Comunidade desenvolveram para lidar com os problemas ambientais do seu cotidiano, como as restrições sazonais de água. A descrição D14 (Sujeito de 32 anos, sexo masculino) ilustra este fenômeno:

a água é meio difícil, porque no inverno tem dias que tá para boa, enche a caixa. Mas tem dias que tá pouquinha. No verão é pouquinha. O poço seca. Corremos atrás desse negócio! Os vereadores para brigar não tão muito pelejando, o trem tá difícil! A terra, o trem tá bom. Nós arrocha aí mesmo [...]

Aplicando a redução fenomenológica, percebe-se que, para esse sujeito, apesar das adversidades ambientais (escassez de água entre os meses de maio a outubro), os moradores buscam alternativas por meio do apoio de políticos para solucionar o problema. Quanto à produção agrícola, destaca o êxito que possuem, apesar das dificuldades por vezes encontradas.

A água, embora não seja um recurso abundante, possibilita a manutenção da Comunidade. Esse recurso é proveniente do Córrego Brejo Grande, que corta a sua área, além de poços cavados, na maioria das vezes, pelos próprios moradores, uma vez que não há uma companhia de abastecimento público de água que atenda à Comunidade. No caso do Córrego Brejo Grande, há indícios de contaminação na água por conta da influência de um depósito de resíduos sólidos (lixão) no município vizinho de Lagoa do Tocantins, à

\footnotetext{
8 Este termo foi empregado no mesmo sentido em que o faz Cangussu (2008), ou seja, como a capacidade que os seres humanos possuem para superar as adversidades que encontram e adaptarem-se às suas circunstâncias de vida.
} 
montante da Comunidade. Esse fato tem restringido o tradicional uso do curso d'água pelos moradores, especialmente na época chuvosa, quando acreditam haver maior carreamento de contaminantes para a calha fluvial. Embora sejam legítimos seus direitos de acesso às políticas públicas, como o atendimento por parte da rede de abastecimento público de água, é inegável que a presença de impactos ambientais na área da Comunidade e no seu entorno poderá representar o agravamento de sua dependência por soluções externas e por bens obtidos junto ao mercado convencional, reduzindo suas possibilidades de auto-sustentação.

Uma essência revelada a partir da redução fenomenológica da descrição D6, de uma anciã (Sujeito de 71 anos, sexo feminino), é a de que hoje há uma facilidade para o cultivo da terra, em comparação com tempos passados, pois se tornou viável o uso de insumos agrícolas para o plantio, algo que necessariamente não estava disponível em sua juventude, por exemplo. Nesse sentido, as melhorias técnicas podem tornar a lida no campo menos penosa na atualidade, apesar de que o acesso a essas técnicas demanda, via de regra, sua aquisição no comércio, por meio de políticas públicas de extensão rural ou de assistência agropecuária. A sua descrição, demonstra esse aspecto: "Hoje em dia tá muito mais fácil, mas a gente é da roça mesmo. Eu não tô indo definitivo, mas meu trabalho é na roça, mas a coisa melhorou. Capinar, ciscar, plantar o arrozinho (faz o gesto e o som de espalhar o arroz no solo)".

A redução fenomenológica dessa descrição indica ainda que a terra é o meio de subsistência primordial da Comunidade. Esse sujeito, por conseguinte, enfatiza o modo de vida rural da Comunidade. O uso do diminutivo "arrozinho" e a forma pela qual se expressa podem indicar intimidade e carinho para com o alimento, salientando que ela domina seu cultivo e o valoriza como fonte de subsistência.

Conforme a descrição $\mathrm{D} 5$, o meio ambiente também foi percebido como a base para o cultivo da terra por um ancião (Sujeito de 62 anos, sexo masculino), afirmando que: "A gente é da roça mesmo! Têm farinha algumas horas. A gente trabalha neste sol louco...".

Por meio da redução fenomenológica, pode-se perceber que o sujeito destaca a terra como meio de subsistência para a Comunidade, apontando, ainda, que em alguns momentos acontece o processamento 
da produção agrícola, como a produção da farinha de mandioca. Faz menção à dificuldade de trabalho no forte calor, típico do Estado do Tocantins. A natureza fornece o alimento, mas em troca do trabalho. Nessa descrição, o modo de vida rural é enfatizado mais uma vez. Assim, além da natureza como fonte de subsistência, sua descrição aponta essencialmente a questão do trabalho para o cultivo da terra.

Tais constatações por parte desses anciões assinalam que a Comunidade, ao mesmo tempo em que se depara com novas perspectivas para seu futuro, numa perspectiva de desenvolvimento local, como concebido por Tenório (2007), carrega consigo uma gama de saberes e vivências ancestrais no cultivo da terra e nas relações com o meio ambiente, o que a caracterizou desde a sua gênese. Este é um momento singular na sua história e que possivelmente revela a necessidade de buscar a preservação e a ressignificação da sua própria identidade quilombola.

Uma essência identificada a partir da redução fenomenológica da descrição (D11) de um dos sujeitos (52 anos, sexo feminino) revelou a sua resignação frente aos impactos ambientais observados na Comunidade, admitindo pouca margem de ação nesses casos. A sua descrição ilustra essa percepção:

a natureza oferece também o pequi que é uma comida muito especial para nós quilombolas e também do pequi a gente tira o óleo que serve de remédio, faz o sabão também. Menino, se a gente for falar tudo o que a natureza oferece (risos)... Dá vontade de chorar quando a gente vê aquelas grandes derrubadas destruindo a natureza. Dá vontade de chorar porque quanto pé de pequi que vai, pé de murici, mangaba e assim por diante, mas fazer o que né.

Nesse sentido, talvez as relações de parentesco e de cordialidade entre os moradores se configurem como empecilhos para iniciativas de oposição por ocasião de impactos promovidos pelos próprios pares. Não obstante, os impactos ambientais promovidos por um membro da Comunidade ou por um proprietário de terras vizinhas poderão implicar em repercussões de escalas mais amplas, podendo vir a afetar a totalidade de indivíduos que, nessa área, dependem diretamente dos recursos naturais para a sobrevivência. Por esse motivo, destaca-se o papel a ser desempenhado pelos organismos responsáveis, no sentido 
de fornecer orientações quanto às formas de manejo mais adequadas para esses recursos e de exercer a fiscalização necessária ao fiel cumprimento das normas ambientais vigentes, não de modo a romper com os saberes tradicionais desse povo quilombola, mas para construir parcerias e trocar experiências.

\section{Considerações finais}

Por meio deste artigo pretendeu-se contribuir para esclarecer como acontecem e são percebidos pelos membros da Comunidade os processos econômicos que desenvolvem e as relações que a partir dele estabelecem com o meio ambiente e a sociedade. Outro objetivo buscado foi identificar as suas contribuições em relação às práticas da economia ecológica, bem como detalhes a serem levados em consideração na elaboração de projetos que venham a atender às necessidades específicas de comunidades remanescentes de quilombos nos eixos a que se predispôs a pesquisa.

Desse modo, buscou-se, por meio da identificação das principais essências das descrições obtidas, traçar um panorama dos aspectos subjetivos da relação entre esses sujeitos e o ambiente no qual estão inseridos. Para tanto, lançou-se mão do aporte teórico da economia ecológica, no intuito de se evidenciar as relações observadas com os aspectos da produção, da utilização dos recursos, do manejo ambiental e da sustentabilidade nesta comunidade de origem quilombola. A escolha desse aporte teórico não nos orientou no sentido restrito de uma constatação das práticas econômicas da comunidade pesquisada, a partir das suas categorizações como práticas ecológicas ou convencionais. Pelo contrário, representou um eixo conceitual a partir do qual foram delineadas as interpretações dos aspectos revelados pelos próprios sujeitos, segundo suas percepções, valores e atitudes em relação ao mundo vivido. Nessa linha de raciocínio, foram verificadas tanto práticas que se alinham à perspectiva da economia ecológica quanto elementos que a contrariam, sendo que ambos compõem seu modo de vida atual, fruto da complexa relação entre suas tradições e as rápidas mudanças técnicas e sociais contemporâneas.

A relação com o meio ambiente é intensa na Comunidade, uma vez que ela depende fundamentalmente dos seus recursos para 
subsistir, havendo consciência deste fato por parte dos seus membros, conforme demonstraram as descrições coletadas. Seja no cultivo dos alimentos, na água consumida, nas construções de casas de barro, no uso do telhado de palha de buriti ou na utilização da lenha como combustível para o fogão, a integração com o meio ambiente é parcimoniosa, muito embora nem todos os membros da Comunidade sejam pró-ativos com relação a um manejo ambiental adequado.

Os impactos ambientais verificados na Comunidade, como as queimadas, o corte de árvores e o lixo espalhado em alguns locais, poderiam ser abordados em campanhas de educação ambiental a serem promovidas como forma de articulação da Associação Comunitária com a Escola Municipal (que se localiza na sua área), no sentido de minimizar tais problemas.

Durante gerações, a Comunidade utilizou o meio ambiente de uma forma relativamente sustentável, se comparada aos padrões de consumo da sociedade contemporânea. A introdução de práticas que causam impactos ambientais mais intensos pelos seus próprios moradores (como a adubação química e uso de herbicidas, por exemplo), somadas às pressões externas que se refletem em sua área (como a poluição do Córrego Brejo Grande, por exemplo), pode comprometer a capacidade de suporte do seu meio ambiente, o que, consequentemente, pode repercutir em sua subsistência. Esses aspectos, ainda carentes de aprofundamento, merecem ser tema de futuras pesquisas na Comunidade.

Observa-se que as iniciativas realizadas quanto ao manejo ambiental na Comunidade (como aquelas alinhadas aos princípios da permacultura e da economia ecológica), embora perceptíveis, são, na maioria das vezes, destituídas de um sentido mais amplo por parte dos moradores. Tanto na Barra da Aroeira como em outras comunidades remanescentes de quilombos, as práticas sustentáveis podem ser acompanhadas por um maior conhecimento dessa temática. A educação ambiental ajudaria muito nesse propósito, qual seja, fazer o morador refletir sobre o significado da sua própria prática em um contexto mais amplo, qualificando-o para agregar valor à produção e ao seu modo de vida, a partir de sua constatação como formas sustentáveis.

O desafio que está posto deste momento em diante é a preservação do modus vivendis tradicional dessa população, o reforço 
de suas práticas sustentáveis e os cuidados para que as inovações não interfiram na sua qualidade socioambiental. Tal desafio exigirá a união e a articulação de esforços, sobretudo por parte das novas gerações, em aprender os saberes desenvolvidos pelos anciões, em harmonia com a incorporação de novos elementos que possam valorizar seu precioso patrimônio imaterial e contribuir para a melhoria da sua qualidade de vida.

\section{REFERÊNCIAS}

BAQUERO, M. A Fragmentação Social na América Latina: formas alternativas para sair da crise. In: BAQUERO, M. (Org.) Capital Social, Desenvolvimento Sustentável e Democracia na América Latina. Porto Alegre: UFRGS, p. 15 - 55, 2007.

BELLO, A. A. Fenomenologia e Ciências Humanas: psicologia, história e religião. Bauru: EDUSC, 2004.

BOAVA, D. L. T.; MACEDO, F. M. F. Análise do papel da INTUEL no desenvolvimento da ação empreendedora de empresários incubados. In: ENCONTRO DE ESTUDOS SOBRE EMPREENDEDORISMO E GESTÃO DE PEQUENAS EMPRESAS, 2008. Anais... Curitiba, 2008.

CANGUSSU, E. T. A Resiliência nos empreendedores egressos do Banco do Brasil: um estudo fenomenológico. 2008. 113 f. Dissertação (Mestrado em Administração), Universidade Estadual de Londrina, Londrina, 2008.

CAPRA, F. As Conexões Ocultas: Ciência para uma vida sustentável. São Paulo: Cultrix, 2002.

O Ponto de Mutação: a ciência, a sociedade e a cultura emergente. São Paulo: Cultrix, 2006.

CARVALHO, J. L. F.; VERGARA, S. C. A Fenomenologia e a pesquisa dos espaços de serviços. Revista de Administração de Empresas, São Paulo, v. 42, n. 3, Jul./Set. 2002, p. 78-91. 
CECHIN, A.; VEIGA, J. E. V. O Fundamento central da economia ecológica. In: MAY, P. (org.) Economia do meio ambiente: teoria e prática, 2 ed. Rio de Janeiro: Elsevier/Campus, 2010, p. 33-48.

CHAUÍ, M. S. Vida e Obra. In: HUSSERL, E. Investigações Lógicas: elementos de uma elucidação fenomenológica do conhecimento. São Paulo: Nova Cultural, 2005, p. 05-13.

COLTRO, A. A Fenomenologia: um enfoque teórico para além da modernidade. Caderno de Pesquisas em Administração, São Paulo, v. 1, n. 11,10 Trim. 2000, p. 37-45.

CONAMA. Conselho Nacional de Meio Ambiente. Resoluções CONAMA 1986-1991. Brasília: IBAMA, 1992.

DALY, H. A economia do século XXI. Porto Alegre: Mercado Aberto, 1984.

EISLER, R. A Verdadeira Riqueza das Nações: criando uma economia solidária. São Paulo: Cultrix, 2008.

FERRAZ, M. V. S. Lições do mundo-da-vida: o último Husserl e a crítica ao objetivismo. Scientiae Studia, São Paulo, v. 2, n. 3, 2004, p. 355-372.

GEORGESCU-ROEGEN, N. The entropy law and the economic process. Cambridge: Harvard University Press, 1971.

GIORGI, A. Sobre o Método Fenomenológico Utilizado Como Modo de Pesquisa Qualitativa nas Ciências Humanas: teoria, prática e evolução. In: POUPART, J. et al (org.). A pesquisa qualitativa: enfoques epistemológicos e metodológicos. Petrópolis: Vozes, 2008, p. 386 409.

HOLZER, W. Um estudo fenomenológico da paisagem e do lugar. a crônica dos viajantes no Brasil do século XVI. 1998. Tese (Doutorado em Geografia Humana). Faculdade de Filosofia, Letras e Ciências Humanas, Universidade de São Paulo, São Paulo, 1998. 
HUSSERL, E. Investigações lógicas: elementos de uma elucidação fenomenológica do conhecimento. São Paulo: Nova Cultural, 2005.

Ideias para uma fenomenologia pura e para uma filosofia fenomenológica. 3 ed. Aparecida: Idéias \& Letras, 2006 (Coleção Subjetividade Contemporânea).

A ideia da fenomenologia. Lisboa: Edições 70, 2008 (Textos Filosóficos).

LEGAN, L. A escola sustentável: eco-alfabetizando pelo ambiente. São Paulo: Imprensa Oficial do Estado de São Paulo; Pirenópolis: Instituto de Permacultura e Ecovilas do Cerrado, 2004.

MARTINE, G. O Lugar do espaço na equação população/meio ambiente. Revista Brasileira de Estudos Populacionais. São Paulo, v. 24, n. 2, jul/dez 2007, p. 181-190.

MARTINEZ-ALÍER, J. Da economia ecológica ao ecologismo popular. Blumenau: FURB, 1998.

MELO, M. M. Capitalismo Versus Sustentabilidade: desafio de uma nova ética ambiental. Florianópolis: UFSC, 2006.

M'GONIGLE, R. M. Ecological Economics and Political Ecology: towards a necessary synthesis. Ecological Economics. v. 28, 1999, p. 11-26.

MOREIRA, D. Pesquisa em Administração: origens, usos e variantes do método fenomenológico. Revista de Administração e Inovação, São Paulo, v. 1, n. 1, 2004, p. 5-19.

MOREIRA, D. O método fenomenológico na pesquisa. São Paulo: Pioneira Thomson, 2002.

MUELLER, C. Os economistas e as relações entre o sistema econômico e o meio ambiente. Brasília: UNB/Finatec, 2007. 
PINDYCK, R. S., RUBINFELD, D. L. Microeconomia. São Paulo: Pearson Prentice Hall, 2005.

PIRES, A. P. Amostragem e pesquisa qualitativa: ensaio teórico e metodológico. In: POUPART, J. et al (org.) A pesquisa qualitativa: enfoques epistemológicos e metodológicos. Petrópolis: Vozes, 2008, p. 154-211.

RUSCHEINSKY, A. No conflito das interpretações: o enredo da sustentabilidade. In: _-_--_. (org.) Sustentabilidade: uma paixão em movimento. Porto Alegre: Sulina, 2004.

SANTOS Jr., S. J. dos. Ecovilas e Comunidades Intencionais: Ética e Sustentabilidade no Viver Contemporâneo. In: Encontro da ANPPAS, 3, 2006, Brasília. Anais... Brasília, 2006. 1 CD ROM.

SEN, A. Sobre ética e economia. São Paulo: Companhia das Letras, 1999.

SÖDERBAUM, P. Values, ideology and politics in Ecological Economics. Ecological Economics, v. 28, 1999, p. 161-170.

TENÓRIO, F. G. Desenvolvimento Local. In: _-_-_-. (org.) Cidadania e Desenvo/vimento Local. Rio de Janeiro: FGV; Ijuí: Ed. Unijuí, 2007, p. $71-$ 101.

VENÂNCIO, M., PESSÔA, V. L. S. O Diário de campo e a construção da pesquisa: registro das emoções dos sujeitos envolvidos e a reconstrução de suas histórias de vida e do lugar. In: RAMIRES, J. C. L.; PESSÔA, V. L. S. (org). Geografia e Pesquisa Qualitativa: nas trilhas da investigação. Uberlândia: Assis Editora, 2009, p. 317-336.

WHYTE, A. Guidelines for fields studies in environmental perception. Paris: UNESCO, 1977.

ZACARIOTTI, M. E., SIQUEIRA, S. R., CASTRO, G. G. A Recepção dos processos comunicacionais no Quilombo Barra da Aroeira. In: 
CONGRESSO BRASILEIRO DE CIÊNCIAS DA COMUNICAÇÃO, 32, 2009, Curitiba. Anais... Curitiba, 2009. 1 CD ROM.

Submetido em 20/05/2014

Aprovado em 09/04/2016

\section{Sobre os autores}

\section{Rogério Ferreira Teixeira}

Mestre em Ciências do Ambiente, pela Universidade Federal do Tocantins-Brasil (2012), economista formado pela UFRGS em 1997, fundador e gestor da Comunidade Sustentável Morada da Paz desde 2002, onde dedica-se à implantação e execução de projetos e ações na área de agroecologia, economia ecológica e educação socioambiental.

E-mail: rogeriodamorada@gmail.com

\section{Lucas Barbosa e Souza}

Doutor em Geografia, Docente do Mestrado em Ciências do Ambiente - Universidade Federal do Tocantins.

E-mail: Ibsgeo@uft.edu.br 